\title{
Article \\ The Role of Cations of the Precipitant in the Interaction of Protein Molecules in the Lysozyme Oligomers in Crystallization Solutions
}

\author{
Yuliya V. Kordonskaya ${ }^{1, *}$, Vladimir I. Timofeev ${ }^{2}$, Yulia A. Dyakova ${ }^{1}$, Margarita A. Marchenkova ${ }^{2}$, \\ Yury V. Pisarevsky ${ }^{2}$ and Mikhail V. Kovalchuk ${ }^{1}$ \\ 1 National Research Centre "Kurchatov Institute", 1, Akademika Kurchatova pl., 123182 Moscow, Russia; \\ Dyakova_YA@nrcki.ru (Y.A.D.); koval@ns.crys.ras.ru (M.V.K.) \\ 2 A.V. Shubnikov Institute of Crystallography, Federal Scientific Research Centre "Crystallography and \\ Photonics", Russian Academy of Sciences, 59, Leninskii Prospect, 119333 Moscow, Russia; \\ Timofeev_VI@nrcki.ru (V.I.T.); Marchenkova_MA@nrcki.ru (M.A.M.); Pisarevskiy_YV@nrcki.ru (Y.V.P.) \\ * Correspondence: yukord@mail.ru
}

Citation: Kordonskaya, Y.V.; Timofeev, V.I.; Dyakova, Y.A.; Marchenkova, M.A.; Pisarevsky, Y.V.; Kovalchuk, M.V. The Role of Cations of the Precipitant in the Interaction of Protein Molecules in the Lysozyme Oligomers in Crystallization Solutions. Crystals 2021, 11, 1534. https://doi.org/10.3390/ cryst 11121534

Academic Editors: Hiroaki Tanaka and Borislav Angelov

Received: 1 November 2021

Accepted: 7 December 2021

Published: 9 December 2021

Publisher's Note: MDPI stays neutral with regard to jurisdictional claims in published maps and institutional affiliations.

Copyright: (c) 2021 by the authors. Licensee MDPI, Basel, Switzerland. This article is an open access article distributed under the terms and conditions of the Creative Commons Attribution (CC BY) license (https:/ / creativecommons.org/licenses/by/ $4.0 /)$.

\begin{abstract}
At the moment, the main opinion is that protein crystallization depends mainly on the the precipitant anions, therefore, there have been only few works devoted to the problem of the influence of its cations. Using the molecular dynamics method, we investigated the stability, changes in the compactness and structural transformations of lysozyme dimers and octamers in solutions with different precipitants $\left(\mathrm{LiCl}, \mathrm{NaCl}, \mathrm{KCl}\right.$ and $\mathrm{CuCl}_{2}$ ) in order to study the contribution of cations during crystal formation in more detail. As a result, we found that cations have a rather noticeable effect on the behavior of oligomers: the higher the atomic mass of the cation, the greater the changes in the dimers structures during its dynamics and, according to the data of SAXS experiments, the lower the concentration of dimers. However, for octamers, this dependence is more complicated.
\end{abstract}

Keywords: protein crystallography; molecular modeling; molecular dynamics; precipitant ions

\section{Introduction}

It is well known that successful protein crystallization is typically (as a rule) carried out with the addition of special crystallization agents-precipitants. A number of works (see, for example, [1-4]) have shown that the addition of precipitants leads to a change in the interaction between proteins from repulsion to attraction. However, the mechanisms of interaction between proteins and precipitant ions have not been sufficiently studied.

In a series of papers [5-7], it has recently been established that the addition of precipitants to protein solutions proteins leads to the formation of precursor clusters representing 3D fragments of the crystal structure. In the case of tetragonal modification of lysozyme, crystal octamers are such clusters that are the units of growth of single crystals. In addition to octamers, dimers are formed in crystallization solutions of lysozyme. However, small-angle X-ray scattering (SAXS) methods allow determining only the size of protein oligomers and their concentrations in solutions.

The paper [8] shows the possibility of studying the interaction of protein molecules with each other and with precipitant ions by the example of a lysozyme solution with a sodium chloride precipitant using the molecular dynamics (MD) method as it allows investigating the systems with atomic accuracy and obtaining of a large amount of structural data in details. Further, the stability of dimers and octamers in lysozyme solutions with the addition of sodium chloride as a precipitant was calculated by MD methods in [8]. The approach applied in that work implies MD simulation of oligomers extracted from PDB files of the crystal structures. As a result, the investigation demonstrated the importance of taking into account the positions of precipitant ions incorporated in the crystal structures. However, it considered only solutions with $\mathrm{NaCl}$ precipitant. According to earlier work [9] 
on lysozyme crystallization with five chlorides of $\mathrm{Li}^{+}, \mathrm{Na}^{+}, \mathrm{K}^{+}, \mathrm{Ni}^{2+}$ and $\mathrm{Cu}^{2+}$, the positions of chloride ions and cations were revealed in the lattice.

The main aim of this work was to establish the dependence of the behaviour of lysozyme dimers and octamers on the type of precipitant cation (namely metal) added to the protein solution to initiate crystallization. For this purpose, we simulated the molecular dynamics of lysozyme dimers and octamers in aqueous solutions with different precipitants: $\mathrm{LiCl}, \mathrm{NaCl}, \mathrm{KCl}$ and $\mathrm{CuCl}_{2}$, and then evaluated the stability, the change of the initial structure and compactness of oligomers, based on root mean square fluctuation (RMSF), root-mean-square deviation (RMSD) and radius of gyration $\left(\mathrm{R}_{\mathrm{g}}\right)$ plots, respectively. Furthermore, we compared the simulation results with the experimental ones carried out using small angle $\mathrm{X}$-ray scattering [10].

\section{Materials and Methods}

Dimer and octamer models were derived using PyMol software (Version 1.5 [11]) from the structures of lysozyme tetragonal crystals (HEWL) deposited in the Protein Data Bank. The structures used, obtained with $\mathrm{LiCl}, \mathrm{NaCl}, \mathrm{KCl}$ and $\mathrm{CuCl}_{2}$ precipitants, have PDB ID: 6QX0, 6QWY, 6QWZ and 6QWW, respectively. The precipitant ions bound to the protein in the crystal, which were detected by X-ray crystallography, were retained in the structures (in the pdb files of the oligomers) and the crystalline water was removed.

There are several ways of the extraction of oligomers from the crystal structure, but in our work, we investigated only one type of octamers and dimers, most likely formed in the crystallization solution of lysozyme [12]. Calculation of the ionization states of amino acid residues at $\mathrm{pH} 4.5$ (according to the experimental conditions) was performed using PROPKA server (Version 2.0.0 [13]). All residues that were found in crystals with multiple occupancies have the same probability of being in one of two conformations (A or B), as their occupancy factor is 0.5 . Since there is no privilege, only conformation A was retained.

All calculations and structure preparation were done in the GROMACS software package version 2021 [14] and were performed in the same way for different oligomer models. The Amber ff99SB-ILDN field [15] with new potential parameters for torsion angles was used as the force field. During the equilibration of the system and productive MD simulation, three-dimensional periodic boundary conditions were applied, and the long-range electrostatic interactions were considered by the smooth particle mesh Ewald (PME) summation method [16] with cubic interpolation and grid spacing in Fourier space of $0.16 \mathrm{~nm}$. Noncovalent interactions were considered only for atoms at less than $1 \mathrm{~nm}$ from each other. The bond lengths in the oligomers were constrained using the LINCS algorithm [17].

The prepared oligomer structures were placed in the centre of a cubic simulation box with a minimum distance of $1 \mathrm{~nm}$ between its edge and the protein molecule. The remaining space of the box was filled with TIP4P-Ew water [18] for performing MD calculations using the Ewald summation method. To reproduce the conditions of the crystallization experiment water molecules were replaced with one of the cation types $\left(\mathrm{Li}^{+}\right.$, $\left.\mathrm{Na}^{+}, \mathrm{K}^{+}, \mathrm{Cu}^{2+}\right)$ and $\mathrm{Cl}^{-}$anions so that the precipitant concentration in the box was $0.4 \mathrm{M}$. Using the PME algorithm for calculating long-range electrostatic interactions formally requires the neutrality of the total charge of the molecular system; therefore, the necessary amount of $\mathrm{Cl}^{-}$ions was added to each box. Thus, boxes with $\mathrm{LiCl}, \mathrm{NaCl}$ and $\mathrm{KCl}$ contained approximately the same number of cations and anions (chlorine ions were slightly more due to charge neutralisation), whereas in the case of $\mathrm{CuCl}_{2}$, twice as many chlorine ions were added as copper ions. Since there were no parameters for copper ions in the ff99SBILDN force field, the data on them was included in the residue database (aminoacids.rtp) and the ions topology (ions.itp) files.

As a result, each box with a dimer contained $159 \pm 1$ cations and $175 \pm 4$ chlorine anions (both dissolved in bulk solution and bound to the protein), except for the case with copper, in which 151 copper cations and 327 chlorine ions were added. Each box with an octamer contained from 628 to 684 cations and from 689 to 774 anions, except for the case with copper, in which 627 copper cations and 1360 chlorine ions were added. 
The energy minimization and equilibration of the systems were carried out according to the following protocol. First, to get rid of atomic overlaps in the original crystal structure and those created by the addition of water, the energy of each system was minimized using the steepest descent algorithm (50,000 steps) so that the force acting on any atom did not exceed $1000 \mathrm{~kJ} \cdot \mathrm{M}^{-1} \mathrm{~nm}^{-2}$. The systems were then sequentially equilibrated in NVT- and NPT- ensembles by the modified Berendsen (V-rescale) [19] and ParrinelloRahman methods [20], respectively (for 100 ps each). The integration time step was set at $2 \mathrm{fs}$, and the temperature and pressure were $283 \mathrm{~K}$ and $1 \mathrm{~atm}$. Productive MD was calculated in NPT ensemble (at $\mathrm{P}=1 \mathrm{~atm}, \mathrm{~T}=283 \mathrm{~K}$ ) using modified Berendsen thermostat and Parrinello-Rahman barostat. Integration was carried out by standard leapfrog algorithm [21]. The duration of each of the calculated lysozyme dimer trajectories was 100 ns. Three independent MD simulations were performed for each precipitant.

Before the analysis of the trajectories, artifacts arising from quasi-infinite periodic boundary conditions were removed by using the gmx trjconv command with the $-p b c$ nojump flag to restore the integrity of the oligomers. RMSF, RMSD and Rg were then plotted by running the commands gmx rmsf, gmx rms and gmx gyrate, respectively. The structural alignment of the trajectories of lysozyme atoms to the initial position in the RMSD calculation was performed by the command gmx trjconv with the flag - fit rot + trans excluding the movement of the protein as a solid body (parallel transfers and rotations around the axis) because it does not affect its conformational changes. For each curve in the RMSF, RMSD and Rg plots, the values were averaged over three independent simulations.

\section{Results}

The stability of the oligomers was assessed by RMSF plots of the C $\alpha$ atoms. RMSF values serve as a measure of the flexibility of the polypeptide chain, as they indicate the degree of deviation of the $C \alpha$ atoms from their average position. The higher the RMSF value of an atom, the more mobile it is.

From Figure 1 and Table 1 it follows that the most stable dimers are those with sodium and lithium ions - their averaged over all atoms RMSF values are $0.116 \mathrm{~nm}$ (Table 1). Dimers with copper (RMSF is $0.137 \mathrm{~nm}$ ) and potassium (RMSF is $0.138 \mathrm{~nm}$ ) are more flexible. The region of amino acid residues ARG125, GLY126, CYS127, ARG128 and LEU129 of the polypeptide chain A is mainly destabilized when simulated with potassium cations (green curve in Figure 1) and chain B-in case of using copper cations (blue curve). It should be noted that these residues are located on the surface of the protein molecule but do not participate in the formation of covalent or hydrogen bonds between monomers. Moreover, they are far from the interface between monomers; residue LEU129 is terminal in the polypeptide chain. 


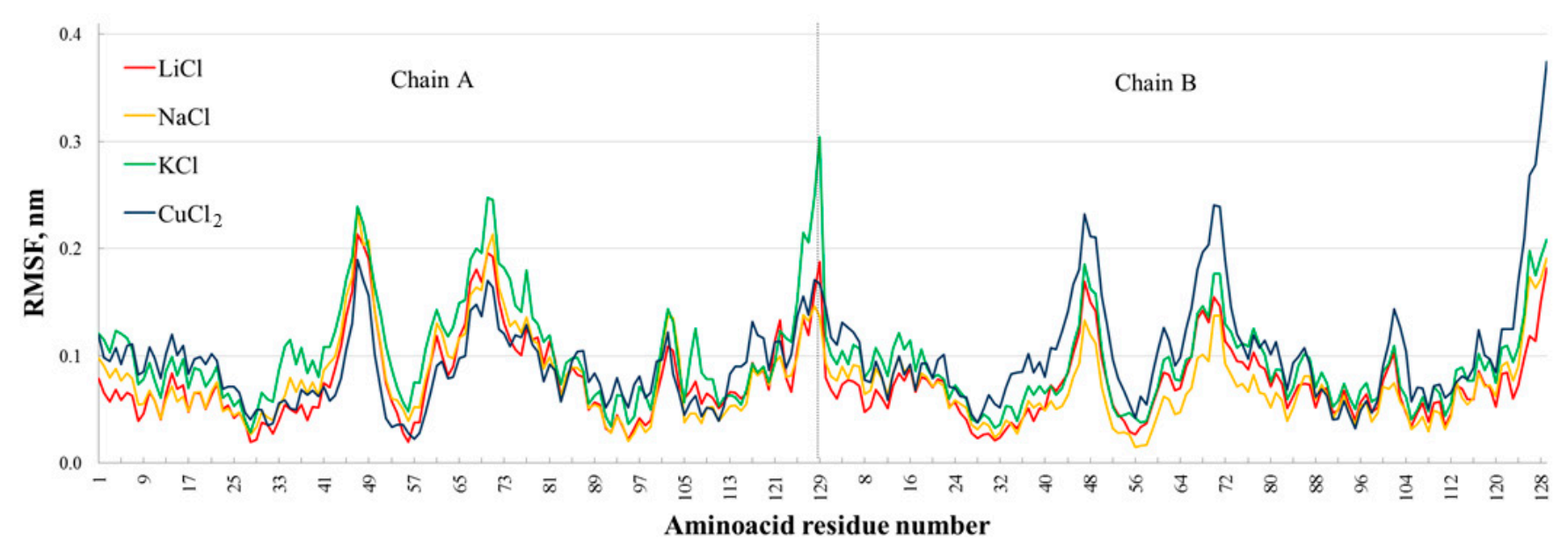

Figure 1. RMSF of dimers with different precipitants: $\mathrm{LiCl}, \mathrm{NaCl}, \mathrm{KCl}$ and $\mathrm{CuCl}_{2}$. Chains $\mathrm{A}$ and $\mathrm{B}$ are the polypeptide chains of dimers.

Table 1. Comparison of concentration, RMSF, RMSD and radius of gyration of dimers averaged over 3 simulations and over all $\mathrm{C} \alpha$ atoms. Given concentration data are obtained from SAXS measurements [10].

\begin{tabular}{ccccc}
\hline Precipitant & Concentration of Dimers, $\%$ & Average RMSF, $\mathbf{n m}$ & Average RMSD, nm & Average $\mathbf{R}_{\mathbf{g}, \mathbf{n m}}$ \\
\hline $\mathrm{LiCl}$ & 13.1 & 0.116 & 0.21 & 2.00 \\
$\mathrm{NaCl}$ & 10.6 & 0.116 & 0.25 & 2.02 \\
$\mathrm{KCl}$ & 10.5 & 0.138 & 0.25 & 2.03 \\
$\mathrm{CuCl}$ & 3.5 & 0.137 & 0.31 & 2.06 \\
\hline
\end{tabular}

In Figure 2, the precipitants have different effects on the different polypeptide chains of the octamer. For example, chain " $\mathrm{A}$ " was relatively stable only when the simulation was conducted with copper (blue curve), while chains " $\mathrm{B}$ " and " $\mathrm{C}$ " were mostly destabilized by sodium (yellow curve).

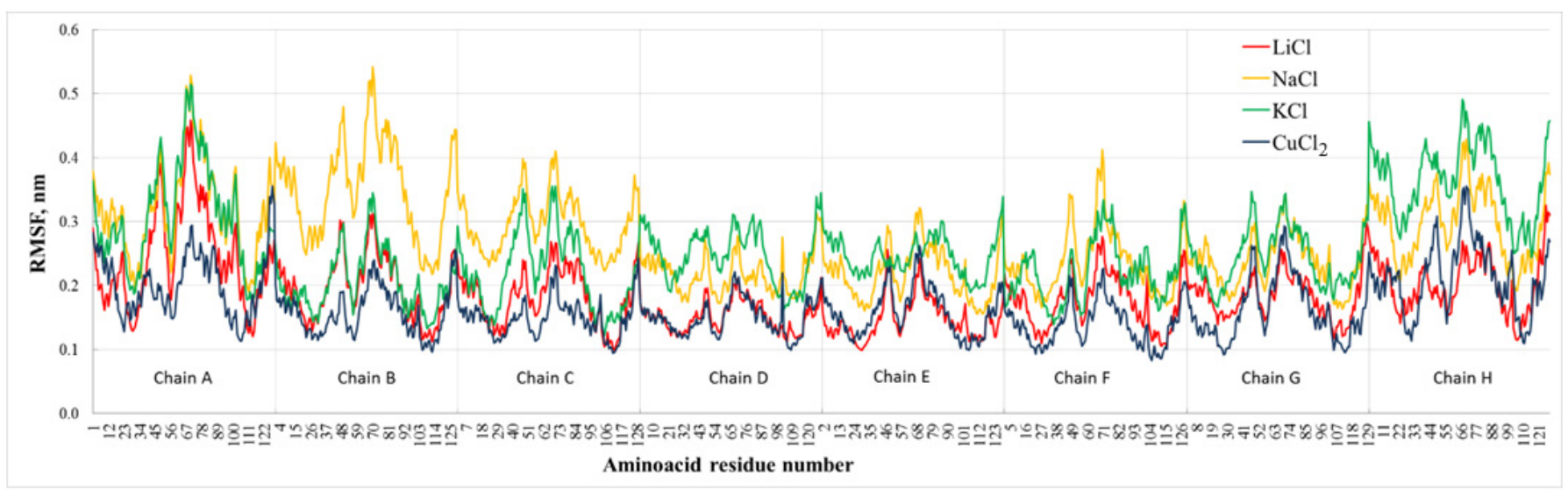

Figure 2. RMSF of octamers with different precipitants: $\mathrm{LiCl}, \mathrm{NaCl}, \mathrm{KCl}$ and $\mathrm{CuCl}_{2}$. Chains $\mathrm{A}-\mathrm{H}$ are the polypeptide chains of octamers.

From Figure 2 and Table 2 it is noticeable that the most stable octamers are with copper and lithium whereas octamers with potassium and sodium are the least rigid. 
Table 2. Comparison of concentration, RMSF, RMSD and radius of gyration of octamers averaged over 3 simulations and over all $\mathrm{C} \alpha$ atoms. Given concentration data are obtained from SAXS measurements [10]. In cases when octamers dissociated into smaller oligomers, there are RMSF values averaged over only two simulations in which the octamers remained as the whole given in brackets.

\begin{tabular}{ccccc}
\hline Precipitant & Concentration of Octamers, $\%$ & Average RMSF, $\mathbf{n m}$ & Average RMSD, $\mathbf{n m}$ & Average $\mathbf{R}_{\mathbf{g}}, \mathbf{n m}$ \\
\hline $\mathrm{CuCl}_{2}$ & 1.7 & 0.166 & 0.32 & 3.29 \\
$\mathrm{LiCl}$ & 1.9 & 0.185 & 0.34 & 3.28 \\
$\mathrm{NaCl}$ & 2.2 & $0.272(0.224)$ & 0.50 & 3.36 \\
$\mathrm{KCl}$ & 2.4 & $0.257(0.19)$ & 0.45 & 3.34 \\
\hline
\end{tabular}

It should be noted that the three independent simulations for both octamers with sodium and octamer with potassium are quite different from each other, unlike the MD of octamers with lithium and copper, as demonstrated in Figure 3.

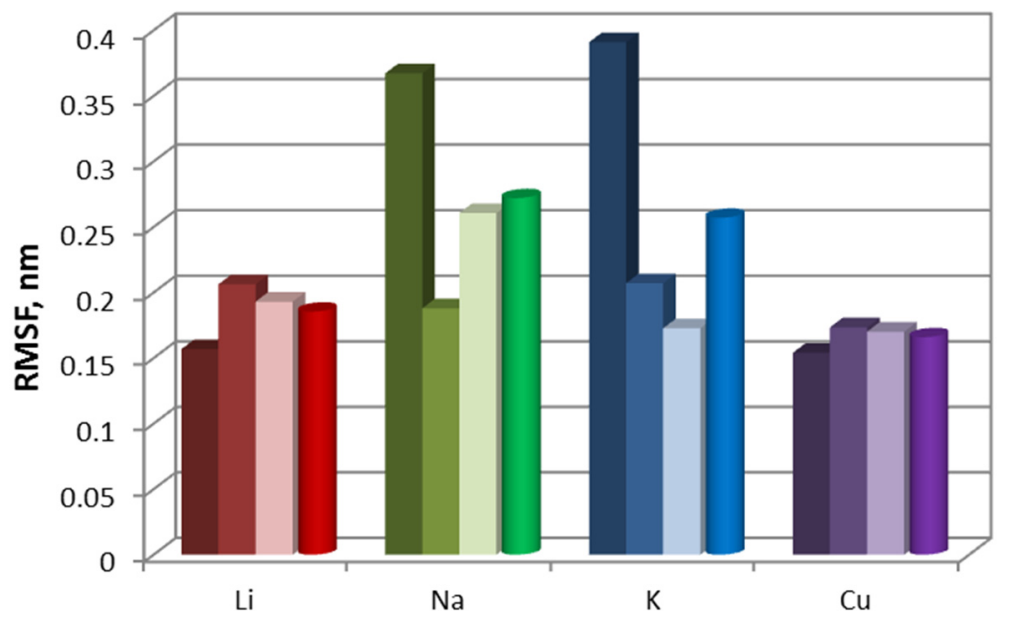

Figure 3. RMSF averaged over all atoms of octamers with different precipitants: $\mathrm{LiCl}, \mathrm{NaCl}, \mathrm{KCl}$ and $\mathrm{CuCl}_{2}$. The first three columns for each precipitant correspond to one of the three independent simulations, the fourth round column is the RMSF value averaged over all atoms as well as over the three simulations.

The change of oligomer structure during molecular dynamics was evaluated based on RMSD plots, i.e., root-mean-square deviation of all $C_{\alpha}$ atoms from the initial (in our case crystalline) structure. The difference between RMSF and RMSD is that RMSF reflects the fluctuations of each atom around its average position over the entire simulation time, while RMSD reflects the deviation of all atoms as a function of time.

Figure 4 and Table 1 show that most of all, especially starting from the 60th ns, the dimer with copper is destabilized (RMSD 0.31 nm). The structure of the dimer with lithium (RMSD 0.21 nm) remained the most similar to the initial one (as in the crystal) throughout the simulation. Dimers with sodium and potassium, although they underwent significant transformations in the course of dynamics, have an RMSD of $0.25 \mathrm{~nm}$ on average over $100 \mathrm{~ns}$. As can be seen from Table 1, the dependence of RMSD on the type of cation is almost ideally correlated with the experimental results on the study of precrystallization solutions of lysozyme using SAXS, since the more the dimer is destabilized, the lower its concentration. 


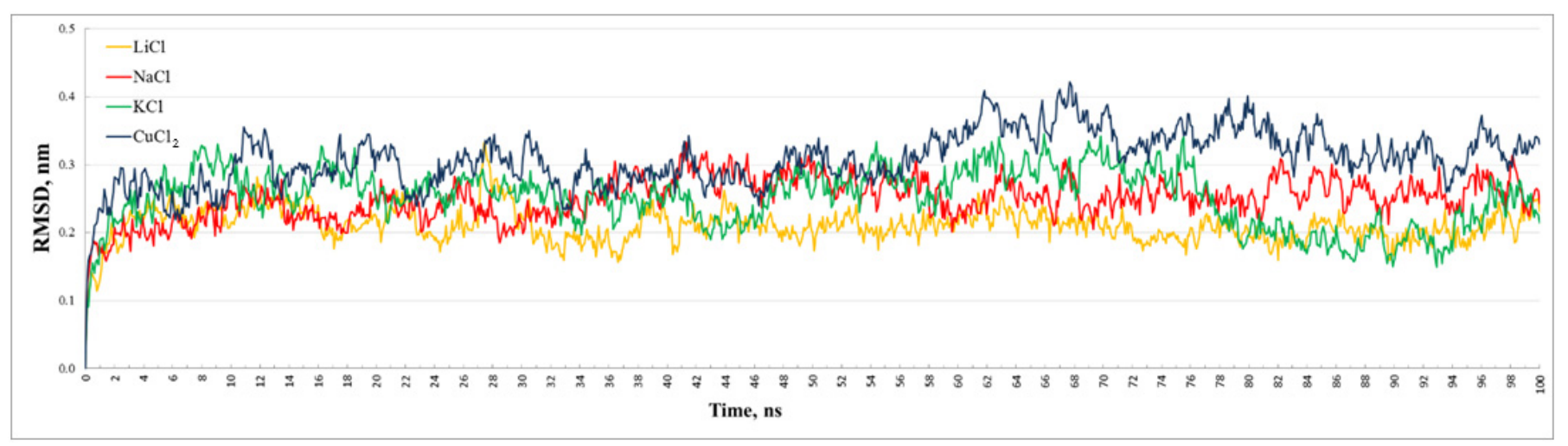

Figure 4. RMSD of dimers with different precipitants: $\mathrm{LiCl}, \mathrm{NaCl}, \mathrm{KCl}$ and $\mathrm{CuCl}_{2}$.

In Figure 5, the RMSDs of octamers with sodium and potassium increase with time, i.e., these clusters did not manage to reach their equilibrium states in $100 \mathrm{~ns}$, and their structures changed dramatically. The lithium and copper octamers retained the best similarity to their initial structures (derived from the crystal).

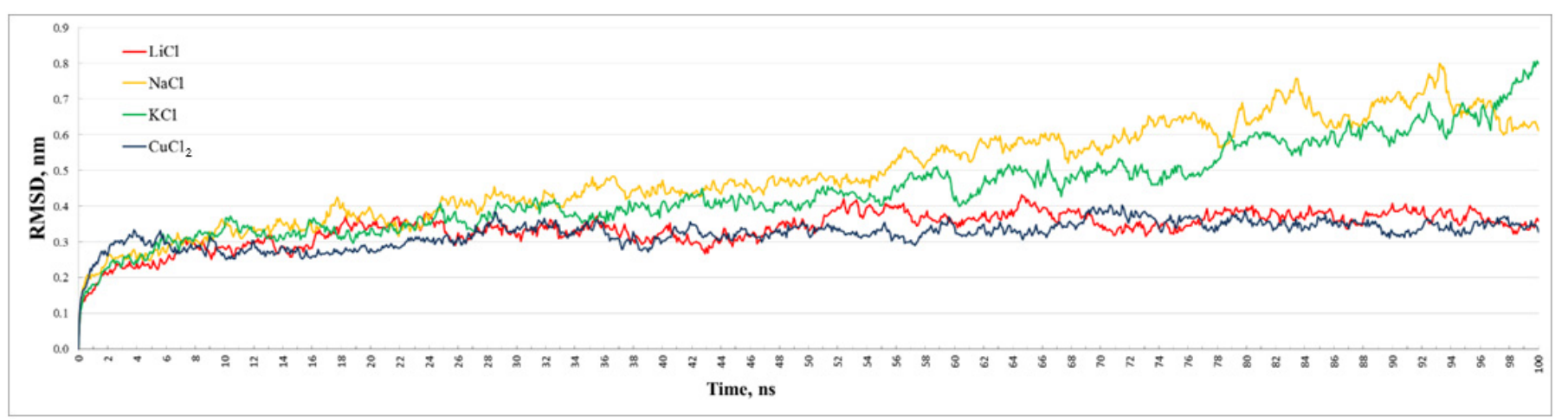

Figure 5. RMSD of octamers with different precipitants: $\mathrm{LiCl}, \mathrm{NaCl}, \mathrm{KCl}$ and $\mathrm{CuCl}_{2}$.

The radius of gyration characterizes the size (compactness) of a protein. It is calculated as the root-mean-square distance of all the atoms in the protein from the centre of mass of the molecule.

From Figure 6 and Table 1, it follows that the dimer with copper remained the least compact during almost the entire dynamics, while the dimer with lithium, on the contrary, thickens slightly with time. The volumes of dimers with sodium and potassium, on average, take intermediate values, despite the fact that they underwent noticeable changes. However, all dimers generally retain their sizes, and the radii of gyration vary within $0.15 \mathrm{~nm}$ (from 1.96 to $2.11 \mathrm{~nm}$ ). 


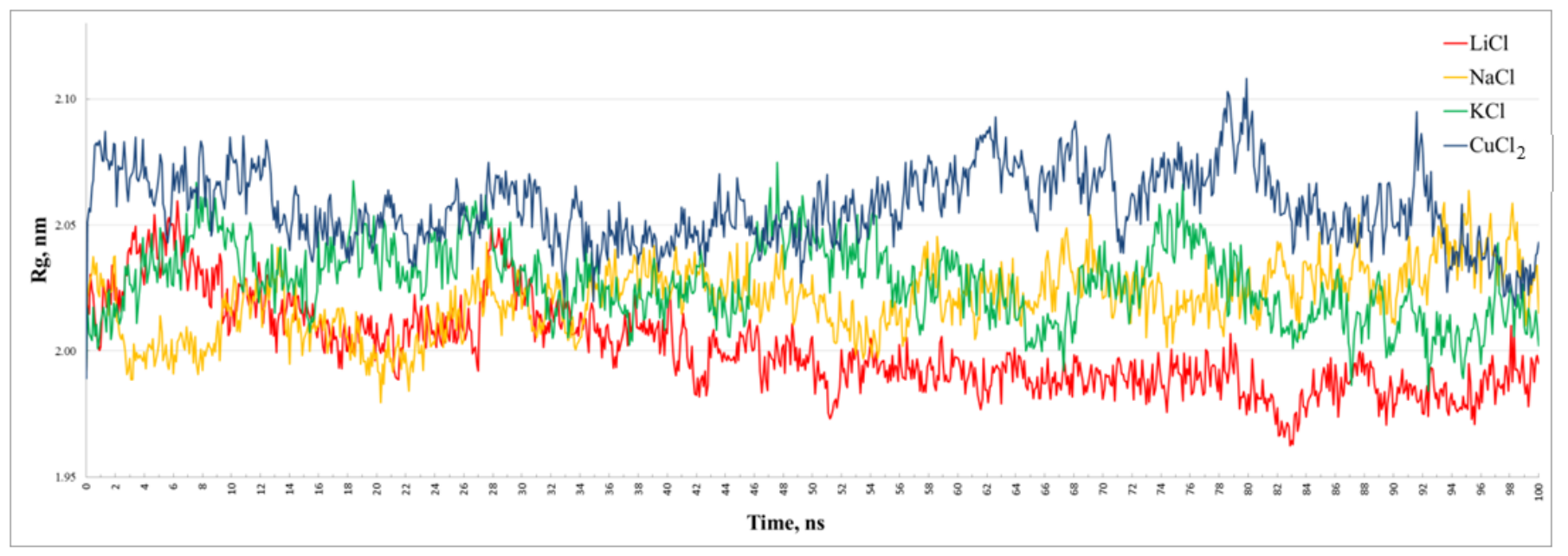

Figure 6. Radii of gyration of dimers $\left(\mathrm{R}_{\mathrm{g}}\right)$ with different precipitants: $\mathrm{LiCl}, \mathrm{NaCl}, \mathrm{KCl}$ and $\mathrm{CuCl}_{2}$.

Table 1 and comparison of the plots of the radius of gyration and RMSD of the dimers show that they correlate: with an increase in RMSD, $\mathrm{R}_{\mathrm{g}}$ also grows, while the root-meansquare deviations of dimers with sodium and potassium, as well as their compactness, are approximately the same.

In Figure 7, the sizes of the sodium and potassium octamers increase the most, their radii of gyration varying in the range of $0.3 \mathrm{~nm}$. Lithium octamer practically does not change its compactness throughout the whole simulation; its radius of gyration fluctuates within $0.1 \mathrm{~nm}$. The volume of octamer with copper remains the most constant throughout the 100 ns dynamics, although it noticeably increases already in 3 ns, after which its $R_{g}$ vary in the range of $0.06 \mathrm{~nm}$.

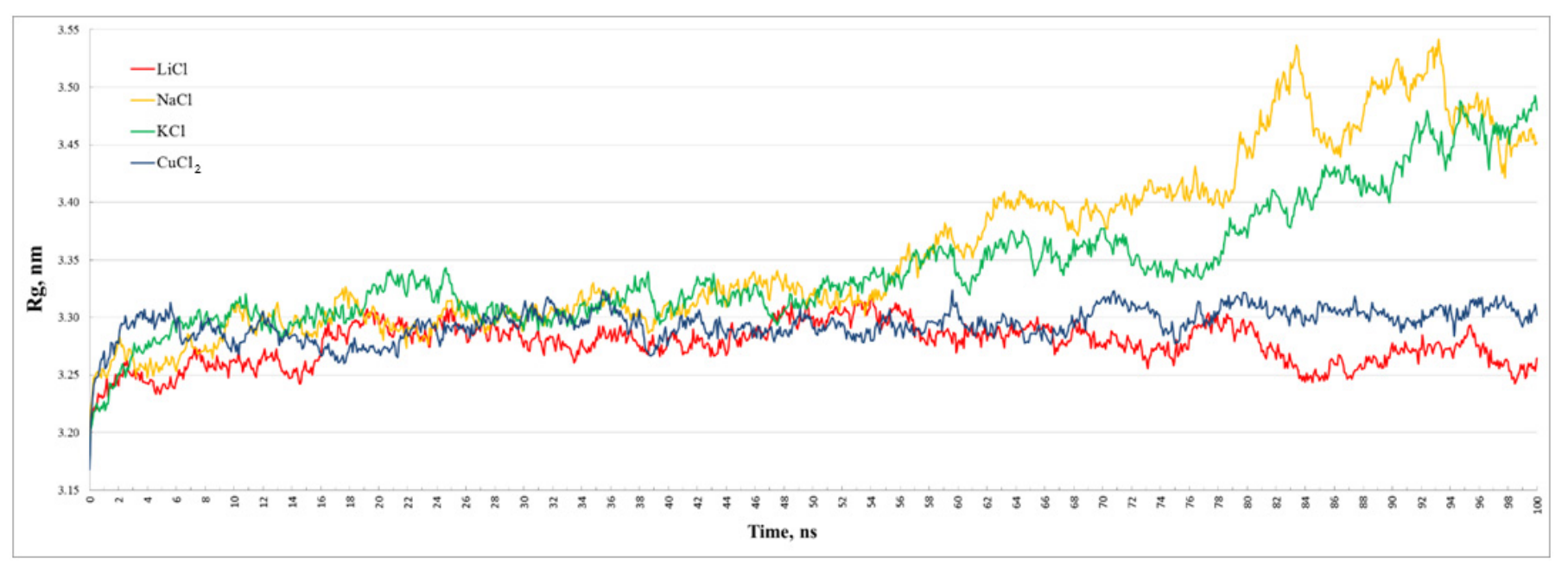

Figure 7. Radii of gyration of octamers $\left(\mathrm{R}_{\mathrm{g}}\right)$ with different precipitants: $\mathrm{LiCl}, \mathrm{NaCl}, \mathrm{KCl}$ and $\mathrm{CuCl}_{2}$.

Finally, Figures 8 and 9 represent a comparison of the temperature B-factor with the RMSF obtained from the MD simulation. It is noticeable that the B-factors of dimers significantly correlate with RMSFs (Figure 8). In the case of octamers, the correlation is worse, which can be explained by the movement of monomers included in octamers relative to each other during MD (Figure 9). 

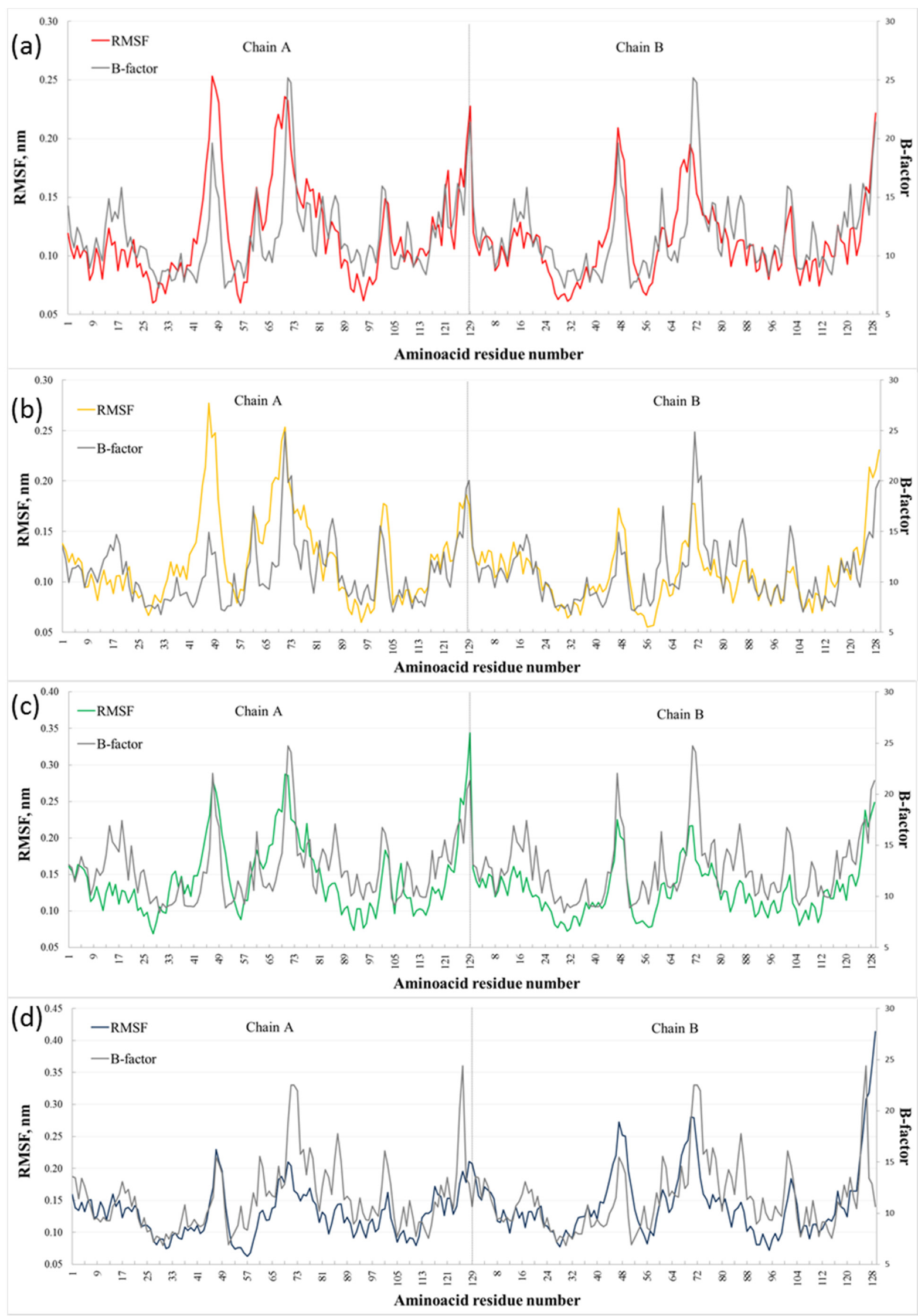

Figure 8. Comparison of the temperature B-factor with the RMSF of dimers with different precipitants: $\mathrm{LiCl}(\mathbf{a}), \mathrm{NaCl}(\mathbf{b})$, $\mathrm{KCl}(\mathbf{c})$ and $\mathrm{CuCl}_{2}$ (d). Chains $\mathrm{A}$ and $\mathrm{B}$ are the polypeptide chains of dimers. 

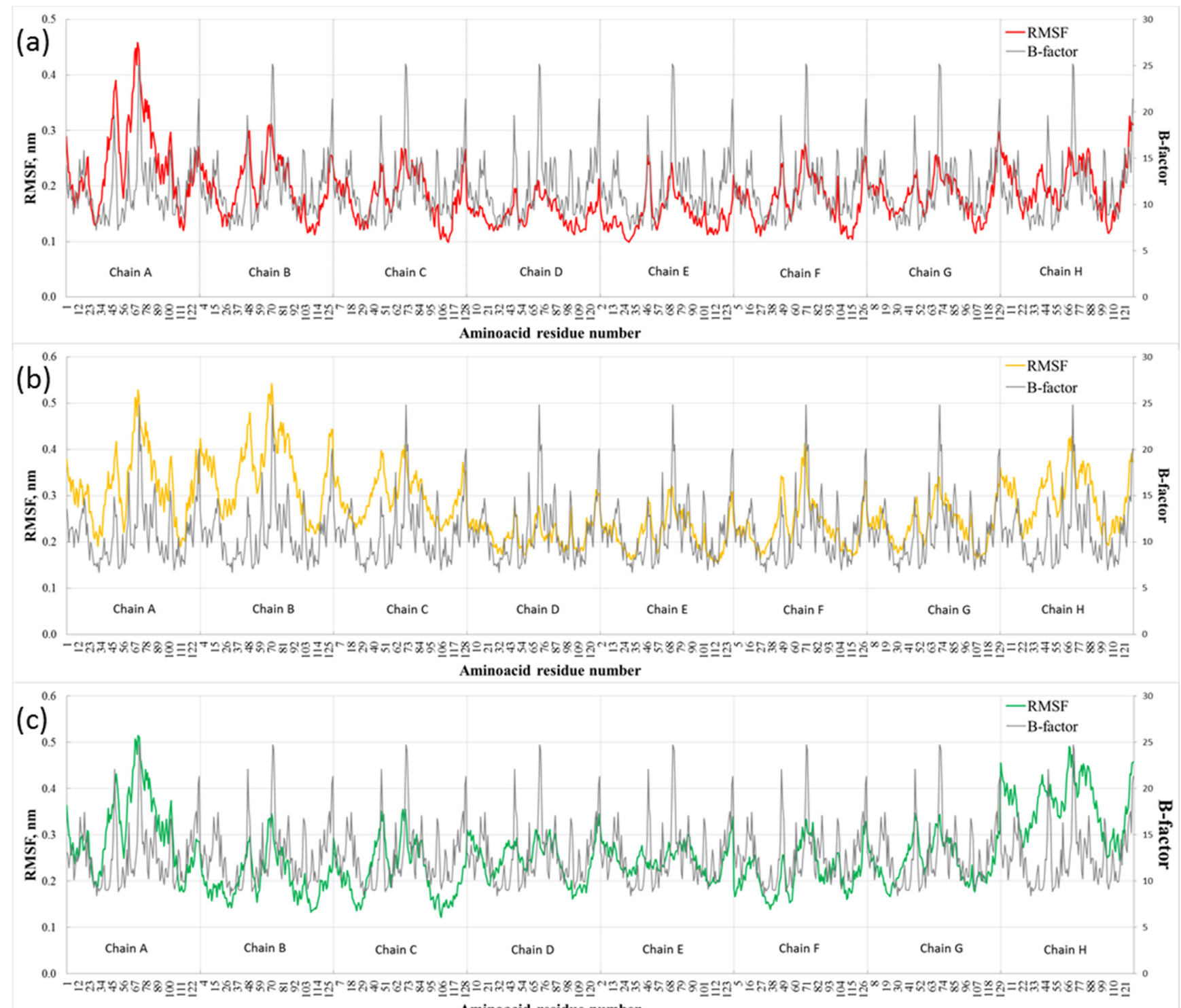
Aminoacid residue number

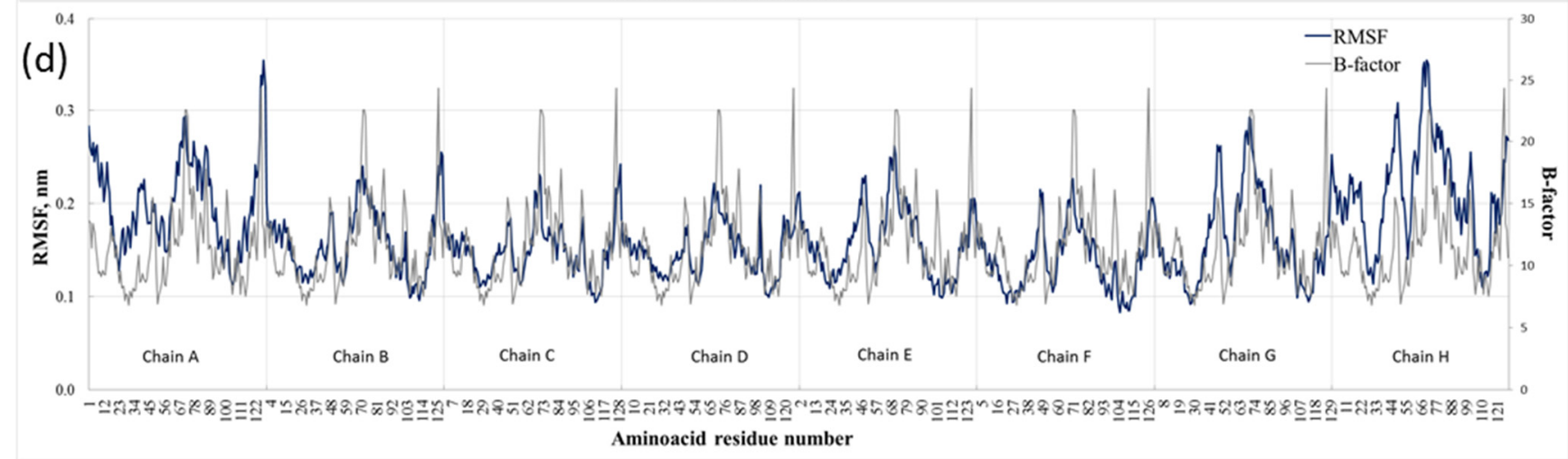

Figure 9. Comparison of the temperature B-factor with the RMSF of octamers with different precipitants: $\mathrm{LiCl}(\mathbf{a}), \mathrm{NaCl}(\mathbf{b})$, $\mathrm{KCl}(\mathbf{c})$ and $\mathrm{CuCl}_{2}$ (d). Chains $\mathrm{A}-\mathrm{H}$ are the polypeptide chains of octamers. 


\section{Discussion}

Comparison of concentration and plots of RMSF, RMSD and radius of gyration of dimers (Table 1) shows that concentration strongly correlates with RMSD and radius of gyration while the RMSF results do not correspond to the experimental ones (SAXS) to this extent (so well), though the agreement is still satisfactory. The fact that RMSF data do not correlate with concentration ones, as well as RMSD and radius of gyration dependences, may, firstly, indicate that the structures of dimers appearing in solutions before lysozyme crystallization are very close to crystalline. Secondly, the RMSD and radius of gyration results seem to be more reliable than RMSF data during the investigation of pre-crystallization oligomers by molecular dynamics. Overall, the dependence of dimers' behaviour in solutions before lysozyme crystallization on precipitant cations is confirmed.

From a comparison of RMSF, RMSD and radius of gyration of octamers on Figure 2 and Table 2, it follows that they correlate- the most rigid molecules are with copper and lithium (their average RMSFs are 0.166 and $0.185 \mathrm{~nm}$, respectively), whereas the clusters modelled with sodium and potassium are the least stable. However, the experimentally observable concentration of octamers is the lowest in the case of lithium and copper and the highest when modelling with sodium and potassium.

In Figure 3, for the potassium and sodium octamers, the largest contribution to the average RMSF is made by the first simulation, during which octamers began to decompose into smaller oligomers as visual inspection of the trajectories revealed. Their average RMSFs are 0.257 and $0.272 \mathrm{~nm}$, respectively. However, even if these simulations are accidental, the results are reliable as RMSFs averaged over two other simulations equal to $0.19 \mathrm{~nm}$ for potassium and $0.224 \mathrm{~nm}$ for sodium; therefore, octamers with these precipitants are still the most unstable. Nevertheless, even considering the data excluding simulations when octamers dissociate, the results are in a disagreement with the experimental ones as the more the octamer structure changes during the dynamics, the higher its concentration. Moreover, taking into account all three independent simulations for each type of precipitant leads to an absence of correlation.

The reason for the correspondence of simulation results to the experimental ones only for dimers and not for octamers can be in the fact that dimers and octamers both were modelled in solutions with the precipitant concentration of $0.4 \mathrm{M}$, whereas octamers probably form after dimers when precipitant concentration is higher than $0.4 \mathrm{M}$.

While in the work [2] there was no significant effect of cation nature of precipitant on the ability to switch protein interactions to attractive ones found, but a number of chlorine anions incorporated in crystal (and oligomers) structures undoubtedly depend on cation type of the precipitant (Table 3 and Figure 10). Nevertheless, the positions of $\mathrm{Cl}^{-}$did not change with varying $\mathrm{NiCl}_{2}$ concentrations, whereas it affected a number of $\mathrm{Ni}^{2+}$ [22]. The monomer extracted from the lysozyme crystal grown from the $\mathrm{LiCl}$ solution has the least number (three) of chlorine ions bound to it, whereas structures corresponding to the $\mathrm{CuCl}_{2}$ solution have the most number of them (six per monomer). $\mathrm{NaCl}$ and $\mathrm{KCl}$ lysozyme monomers incorporate four and five chlorine ions, respectively. It should be noted that lithium and potassium cations are absent in the lysozyme structures. Lithium ions may not be detected by X-ray structural analysis, whereas potassium ions might be too large to incorporate in the protein but they force more chlorine anions (five per monomer) to associate with lysozyme (Table 3 and Figure 10).

From [3], it is known that a majority of anion sites are observed in all lysozyme crystals, whatever their form or precipitant nature is, while there is no site that is common to all structures. However, analysis of structures of oligomers considered above showed that chorine ions are always present in three constant sites (SER-24, GLY-26, GLN-121; THR-69, ARG-68, GLY-67, SER-72, ASN-65; LYS-33) that may be the most important for lysozyme oligomers forming before tetragonal crystal growth. Additionally, other sites seem to slightly destabilize dimers, since the lower the concentration of dimers is, the more sites are involved. Moreover, a site with chlorine ion bound to residues (TYR-23 and ASN-113) of two different chains might be responsible for octamers sustainability: firstly, this is the 
only site when chlorine ion is associated with two chains simultaneously. Secondly, this site is found only in octamers extracted from lysozyme crystals grown from $\mathrm{NaCl}$ and $\mathrm{KCl}$ solutions, whereas octamers' concentration is the highest in the case of these precipitants. It should be noted that our inferences concern only the relative efficiency of different chlorine sites to influence the stability of lysozyme oligomers considered here as their number and position strongly vary depending on precipitant concentration; see, for example, [23].

Table 3. The presence of chlorine ions in different sites of lysozyme monomer depending on precipitant nature. Every site is designated by the residues to which chloride ion is associated.

\begin{tabular}{|c|c|c|c|c|c|c|c|c|}
\hline Precipitant & $\begin{array}{r}\text { SER-24, } \\
\text { GLY-26, } \\
\text { GLN-121 }\end{array}$ & $\begin{array}{c}\text { THR-69, ARG-68, } \\
\text { GLY-67, SER-72, } \\
\text { ASN-65 }\end{array}$ & LYS-33 & $\begin{array}{c}\text { TYR-23, } \\
\text { ASN-113 }^{1}\end{array}$ & ILE-88 & $\begin{array}{r}\text { LYS-13, } \\
\text { LEU-129 }\end{array}$ & GLY-171 & $\begin{array}{l}\text { Total Number } \\
\text { of } \mathrm{Cl}^{-}\end{array}$ \\
\hline $\mathrm{LiCl}$ & + & + & + & - & - & - & - & 3 \\
\hline $\mathrm{NaCl}$ & + & + & + & + & - & - & - & 4 \\
\hline $\mathrm{KCl}$ & + & + & + & + & + & - & - & 5 \\
\hline $\mathrm{CuCl}_{2}$ & + & + & + & - & + & + & + & 6 \\
\hline
\end{tabular}

${ }^{1}$ The only site with chlorine ion bound to residues belonging to different chains.
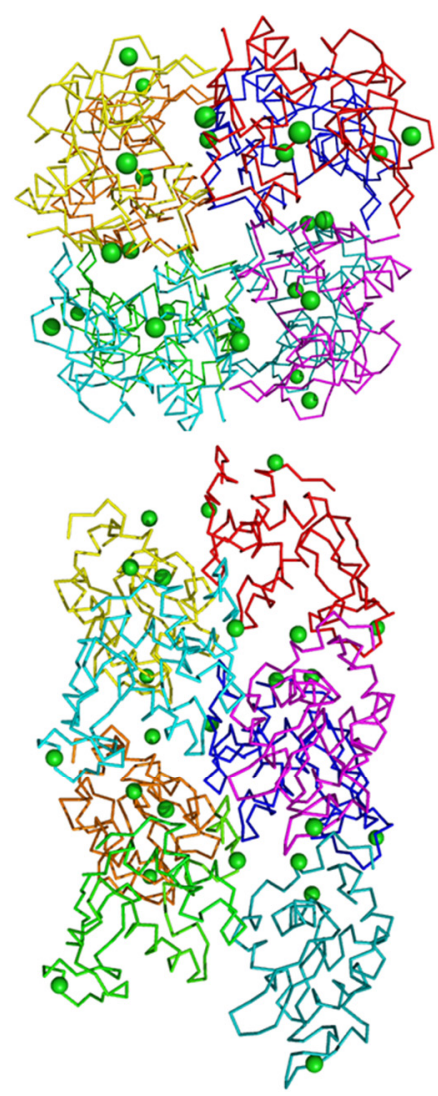

(a)
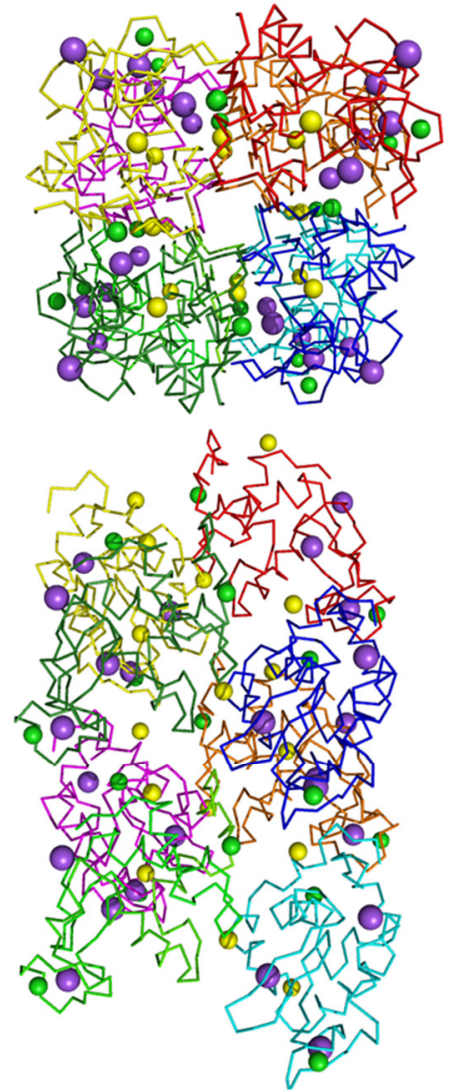

(b)
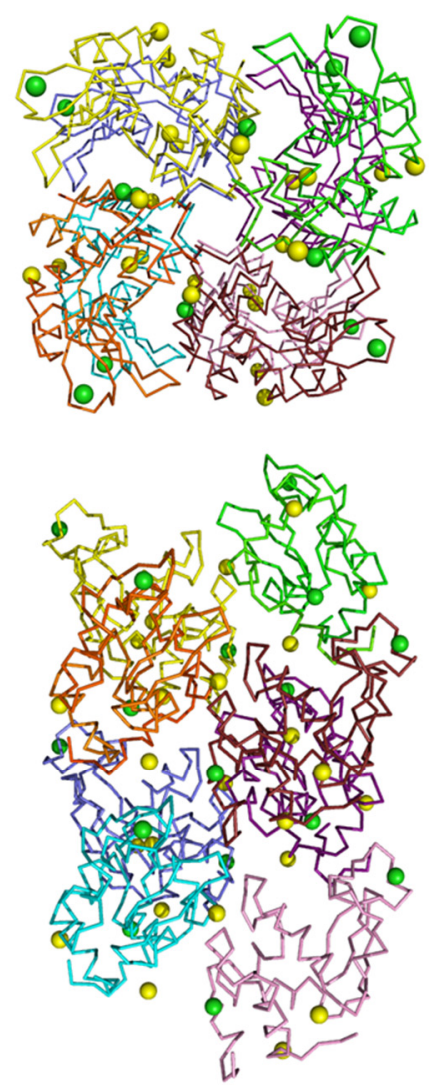

(c)
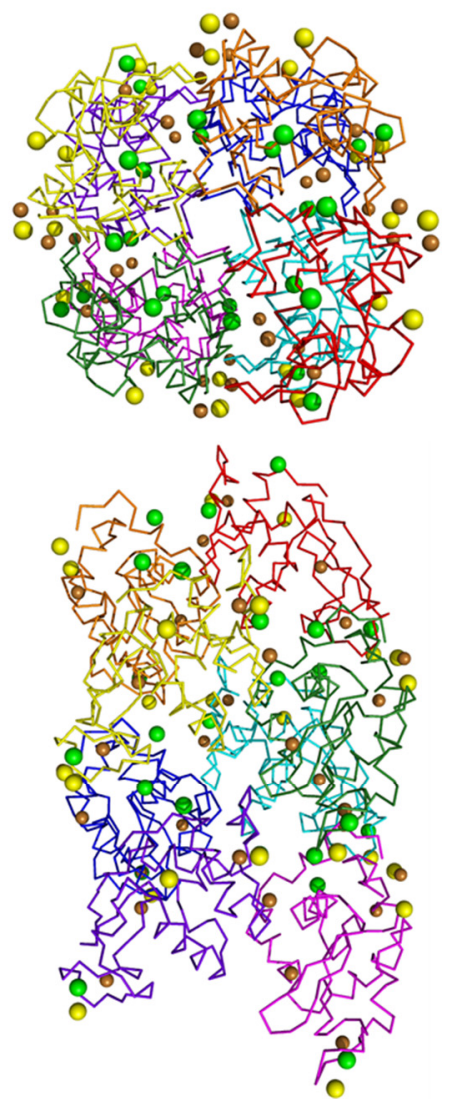

(d)

Figure 10. The distribution of metal and chloride ions in the crystal lattice of lysozyme octamers across (top) and along (bottom) the 4-fold axis. Octamers structures relate to crystals grown in solutions with different precipitants: $\mathrm{LiCl}(\mathbf{a}), \mathrm{NaCl}$ (b), $\mathrm{KCl}$ (c) and $\mathrm{CuCl}_{2}$ (d). All precipitant ions are presented as spheres. Chlorine ions common for all considered structures are green, specific chlorine ions are yellow, sodium ions are purple and copper ions are orange.

\section{Conclusions}

Earlier in the works, it was stated that cations have little effect on the interaction of proteins with each other before crystallization, but the details remained insufficiently 
known. Further on, the formation of a precursor cluster (octamer) and the intermediate phase (dimer) were discovered. This study is devoted to the molecular dynamics of tetragonal lysozyme associates (dimers and octamers) in a solution containing potassium, sodium, lithium or copper cations, as well as chlorine anions in concentration initiating the protein crystallization. It follows from this work that the intermediate phase substantially depends on the cation, while for the octamer this dependence is weak. Therefore, the molecular dynamics allowed studying the subtle details of the interaction and the mechanisms of oligomers' formation. It is interesting to note that the temperature B-factor for dimers correlates well with RMSF, which is not observed for octamers.

Author Contributions: Conceptualization, V.I.T.; methodology, V.I.T.; validation, Y.V.K.; formal analysis, Y.V.K.; investigation, Y.V.K., V.I.T., M.A.M. and Y.V.P.; resources, M.A.M., Y.A.D. and M.V.K.; data curation, Y.V.K.; writing-original draft preparation, Y.V.K..; writing-review and editing, Y.V.K., V.I.T., M.A.M. and Y.V.P.; visualization, Y.V.K.; supervision, Y.V.P. and M.V.K.; project administration, M.A.M.; funding acquisition, M.A.M., Y.A.D. and M.V.K. All authors have read and agreed to the published version of the manuscript.

Funding: This research was funded by Ministry of Science and Higher Education: grant No 075-152021-1362 in a part of calculating molecular dynamics, by the Russian Foundation for Basic Research (project number 19-29-12042 mk) in a part of analyzing the results of computer modeling and the Ministry of Science and Higher Education within the State assignment FSRC «Crystallography and Photonics» RAS in a part of the development of a molecular-modeling protocol.

Acknowledgments: This work has been carried out using computing resources of the federal collective usage center Complex for Simulation and Data Processing for Mega-science Facilities at NRC "Kurchatov Institute", http:/ / ckp.nrcki.ru/ (assessed on 1 November 2021).

Conflicts of Interest: The authors declare no conflict of interest.

\section{References}

1. Ries-Kautt, M.M.; Ducruix, A.F. Relative effectiveness of various ions on the solubility and crystal growth of lysozyme. J. Biol. Chem. 1989, 264, 745-748. [CrossRef]

2. Ducruix, A.; Guilloteau, J.P.; Riès-Kautta, M.; Tardieu, A. Protein interactions as seen by solution X-ray scattering prior to crystallogenesis. J. Cryst. Growth 1996, 168, 28-39. [CrossRef]

3. Vaney, M.C.; Broutin, I.; Retailleau, P.; Douangamath, A.; Lafont, S.; Hamiaux, C.; Prangé, T.; Ducruix, A.; Riès-Kautt, M. Structural effects of monovalent anions on polymorphic lysozyme crystals. Acta Crystallogr. Sect. D Biol. Crystallogr. 2001, 57, 929-940. [CrossRef]

4. Bénas, P.; Auzeil, N.; Legrand, L.; Brachet, F.; Regazzetti, A.; Riès-Kautt, M. Weak protein-cationic co-ion interactions addressed by X-ray crystallography and mass spectrometry. Acta Crystallogr. Sect. D Biol. Crystallogr. 2014, 70, 2217-2231. [CrossRef] [PubMed]

5. Kovalchuk, M.V.; Blagov, A.E.; Dyakova, Y.A.; Gruzinov, A.Y.; Marchenkova, M.A.; Peters, G.S.; Pisarevsky, Y.V.; Timofeev, V.I.; Volkov, V.V. Investigation of the initial crystallization stage in lysozyme solutions by Small-Angle X-ray Scattering. Cryst. Growth Des. 2016, 16, 1792-1797. [CrossRef]

6. Marchenkova, M.A.; Volkov, V.V.; Blagov, A.E.; Dyakova, Y.A.; Ilina, K.B.; Tereschenko, E.Y.; Timofeev, V.I.; Pisarevsky, Y.V.; Kovalchuk, M.V. In situ study of the state of lysozyme molecules at the very early stage of the crystallization process by small-angle X-ray scattering. Crystallogr. Rep. 2016, 61, 5-10. [CrossRef]

7. Boikova, A.S.; D’yakova, Y.A.; Il'ina, K.B.; Konarev, P.V.; Kryukova, A.E.; Marchenkova, M.A.; Blagov, A.E.; Pisarevskii, Y.V.; Koval'chuk, M.V. Small-angle X-ray scattering study of the influence of solvent replacement (from $\mathrm{H}_{2} \mathrm{O}$ to $\mathrm{D}_{2} \mathrm{O}$ ) on the initial crystallization stage of tetragonal lysozyme. Crystallogr. Rep. 2017, 62, 837. [CrossRef]

8. Kordonskaya, Y.V.; Marchenkova, M.A.; Timofeev, V.I.; Dyakova, Y.A.; Pisarevsky, Y.V.; Kovalchuk, M.V. Precipitant ions influence on lysozyme oligomers stability investigated by molecular dynamics simulation at different temperatures. J. Biomol. Struct. Dyn. 2021, 39, 7223-7230. [CrossRef] [PubMed]

9. Marchenkova, M.A.; Kuranova, I.P.; Timofeev, V.I.; Boikova, A.S.; Dorovatovskii, P.V.; Dyakova, Y.A.; Ilina, K.B.; Pisarevskiy, Y.V.; Kovalchuk, M.V. The binding of precipitant ions in the tetragonal crystals of hen egg white lysozyme. J. Biomol. Struct. Dyn. 2020, 38, 5159-5172. [CrossRef]

10. Dyakova, Y.A.; Boikova, A.S.; Ilina, K.B.; Konarev, P.V.; Marchenkova, M.A.; Pisarevsky, Y.V.; Kovalchuk, M.V. Study of the influence of a precipitant cation on the formation of oligomers in crystallization solutions of lysozyme protein. Cryst. Rep. 2019, 64, 11-15. [CrossRef]

11. Schrodinger, L.L.C. The PyMOL Molecular Graphics System; Version 1.5; Schrödinger, Inc.: New York, NY, USA, 2010. 
12. Kordonskaya, Y.V.; Timofeev, V.I.; Dyakova, Y.A.; Marchenkova, M.A.; Pisarevsky, Y.V.; Podshivalov, D.D.; Kovalchuk, M.V. Study of the Behavior of Lysozyme Oligomers in Solutions by the Molecular Dynamics Method. Crystallogr. Rep. 2018, 63, 947-950. [CrossRef]

13. Dolinsky, T.J.; Nielsen, J.E.; McCammon, J.A.; Baker, N.A. PDB2PQR: An automated pipeline for the setup of Poisson-Boltzmann electrostatics calculations. Nucleic Acids Res. 2004, 32, W665-W667. [CrossRef] [PubMed]

14. Van Der Spoel, D.; Lindahl, E.; Hess, B.; Groenhof, G.; Mark, A.E.; Berendsen, H.J.C. GROMACS: Fast, flexible, and free. J. Comput. Chem. 2005, 26, 1701-1718. [CrossRef]

15. Lindorff-Larsen, K.; Piana, S.; Palmo, K.; Maragakis, P.; Klepeis, J.L.; Dror, R.O.; Shaw, D.E. Improved side-chain torsion potentials for the Amber ff99SB protein force field. Proteins Struct. Funct. Bioinforma. 2010, 78, 1950-1958. [CrossRef] [PubMed]

16. Essmann, U.; Perera, L.; Berkowitz, M.L.; Darden, T.; Lee, H.; Pedersen, L.G. A smooth particle mesh Ewald method. J. Chem. Phys. 1995, 103, 8577-8592. [CrossRef]

17. Hess, B.; Bekker, H.; Berendsen, H.J.C.; Fraaije, J.G.E.M. LINCS: A Linear Constraint Solver for molecular simulations. J. Comput. Chem. 1997, 18, 1463-1472. [CrossRef]

18. Horn, H.W.; Swope, W.C.; Pitera, J.W.; Madura, J.D.; Dick, T.J.; Hura, G.L.; Head-Gordon, T. Development of an improved four-site water model for biomolecular simulations: TIP4P-Ew. J. Chem. Phys. 2004, 120, 9665-9678. [CrossRef]

19. Berendsen, H.J.C.; Postma, J.P.M.; Van Gunsteren, W.F.; Dinola, A.; Haak, J.R. Molecular dynamics with coupling to an external bath. J. Chem. Phys. 1984, 81, 3684-3690. [CrossRef]

20. Parrinello, M.; Rahman, A. Strain fluctuations and elastic constants. J. Chem. Phys. 1982, 76, 2662-2666. [CrossRef]

21. Van Gunsteren, W.F.; Berendsen, H.J.C. A Leap-Frog Algorithm for Stochastic Dynamics. Mol. Simul. 1988, 1, 173-185. [CrossRef]

22. Li, S.J.; Nakagawa, A.; Tsukihara, $\mathrm{T}_{\text {. } \mathrm{Ni}^{2+}}$ binds to active site of hen egg-white lysozyme and quenches fluorescence of Trp62 and Trp108. Biochem. Biophys. Res. Commun. 2004, 324, 529-533. [CrossRef] [PubMed]

23. Dauter, Z.; Dauter, M.; de La Fortelle, E.; Bricogne, G.; Sheldrick, G.M. Can anomalous signal of sulfur become a tool for solving protein crystal structures? J. Mol. Biol. 1999, 289, 83-92. [CrossRef] [PubMed] 